\title{
Financial crisis and recession: how \\ ONS has addressed \\ the statistical and analytical challenges
}

Aileen Simkins, Paul Smith

and Martin Brand

Office for National Statistics

\section{SUMMARY}

This article explains some particular statistical issues in measuring the economy during a recession and sets out the ways in which ONS has addressed these challenges, including steps to give users good information and analysis about the changing path of the economy.

\section{Introduction}

he recession, and its particular causes, have raised a number of challenges and opportunities for ONS in maintaining the statistical quality and improving the relevance of our routine outputs and ad hoc analysis. This paper describes the range of responses, including new projects, rapid response methodological advice, special publications and presentations and joint technical work with other departments.

Economic statistics have been of major interest during the financial crisis and recession, not only to analysts and commentators but also to the wider public. Some of the developments described in this article are about steps to meet the needs of wider users, who are interested in the general message and implications rather than the technical detail. The main issues covered, though, are steps taken to verify and, where needed, improve the statistical base of the main ONS economic indicators, and to provide more analysis and interpretation for interested users.

\section{The challenge for ONS outputs}

The recession has affected ONS outputs in a number of ways. The context has been:

- a strong spotlight on all published indicators, with much external economic interpretation of the developing data

- an increased need for ONS to ensure clear presentation of our figures and of the story they tell
- a need to keep a close eye on the technical and methodological basis for economic statistics to ensure they remain valid in changing economic circumstances

- a need for investigation of particular methods and issues, for example on the retail sales index and construction statistics, and work with the Department for Work and Pensions (DWP) on differences between trends in unemployment and the claimant count

- growing recognition that some data sources and analytic approaches, particularly for the financial sector, need improvement in order to understand the mechanics of the credit boom and the securitisation instruments upon which it was built

- increased interest in the extent of revisions to first estimates of key indicators, particularly those relating to GDP

- a strong focus on labour market statistics and interest in extended analyses, for example, of moves in and out of unemployment, analysis by age group and region

- the need for additional work on reclassification of some financial corporations into the public sector, and on the classification of Government financial interventions

- increased focus on the state of the public finances and on public service efficiency/productivity 


\section{ONS response}

To meet these challenges, ONS put in hand several work streams:

- a programme to improve communication of its published outputs and to increase the focus on topical analysis

- work to review methodology across the production process, to see where issues might need to be addressed

- rapid response capacity and teamwork to investigate specific areas in more depth, where and when it became clear that issues were arising, including those raised by users

The rest of this paper reports progress and achievements on this work.

\section{Clear communication, topical analysis}

ONS has improved the coverage of the

Economic Review article in the Economic and Labour Market Review (ELMR) to give a monthly overview of recent ONS economic statistics, with economic interpretation and contextual information. This comments on the past rather than making any predictions for the future; the aim is to be helpful to readers in showing the drivers and connections between different sets of statistics and providing some extra analysis. ELMR will continue to be the main ONS mechanism for publishing economic analytic material. Other key articles in the last year which help explain recent economic events have been: Retail sales in the downturn (March 2009); The impact of the economic downturn on productivity growth (June 2009); Developing financial statistics for policy (special edition, July 2009); Recent developments in the UK housing market (August 2009); The housing market and household balance sheets (September 2009); The balance of payments (September 2009); Recession and recovery in the OECD (October 2009); Unemployment durations (October 2009); Patterns of nonemployment, and of disadvantage, in a recession (December 2009); and The labour market in the recession (January 2010).

ONS statistical bulletins are being progressively improved to ensure the presentation of key statistical messages is clear. They are adopting a common structure: the front page contains the main messages in words, illustrated by a table and chart(s). This ensures key statistics are presented first, without obscuring the main changes by giving full details and technical notes. Following pages include additional information at a more detailed level, a summary of statistical records and a streamlined notes section. Information previously contained in the separate web briefing has also been streamlined and incorporated into the statistical bulletin. The detailed content and presentation of each bulletin has also been reviewed systematically. The new format has been shared with key stakeholders for each bulletin in advance of the change, with positive responses.

ONS aims to improve the visibility of economic material on its website (pending a major website redesign, now in progress). For example a graph comparing output and unemployment in the current and previous recessions is now available, linked both to the Economy and Labour Market pages and via the UK Snapshot (www.statistics.gov.uk/ cci/nugget.asp?id=2294). The website also includes animated maps to show the impact of the recession on the labour market, including the change in the population in each area claiming Jobseeker's Allowance since the start of 2008 (www.statistics.gov. $\mathrm{uk} / \mathrm{lm}$-interactive/). In addition to text on the website, ONS is now beginning to make podcasts (see www.palgrave-journals.com/ fsp/ons_podcast_archive.html).

ONS has arranged several seminars to present the latest analytic work to invited audiences. Examples in 2009 were two events on the labour market in the current recession: the first emphasised historic comparisons, and the second gave more analysis at the sub-national level. Proposed developments to improve finance statistics were presented at a seminar in July, following the special edition of ELMR on the topic. The new Wealth in Britain survey was presented at a seminar in December, explaining the rich new data source on the distribution of assets amongst households, and savings patterns. Developments described in this article will be presented at a seminar in London on 1 February 2010. Readers who wish to attend the seminar on 1 February, or be informed of future events as they are arranged are invited to email Nathanael Jones (nathanael.jones@ons.gsi.gov.uk).

\section{Robust statistical methodology during changes in economic cycle}

ONS has systematically assessed the robustness of our statistical methodology, to ensure that the quality of key indicators does not deteriorate. This has involved review of each stage of the Statistical Value Chain (SVC; www.statistics.gov.
uk/downloads/theme_other/Guidelines_ Subject.pdf, p11) and identified priorities for investigative work to ensure that the quality of UK economic statistics is maintained at a critical time.

The SVC is a simple sequential list of the steps in creating a survey-based statistical output, starting with the decision to undertake a statistical collection or statistical analysis, through to archiving, which ends the cycle. The Annex sets out briefly the 15 stages of the SVC and ONS' scoping of potential effects due to the recession. These are largely, but not exclusively, related to business surveys and economic statistics.

The Annex shows that many of the statistical challenges from the recession are being dealt with effectively by statistical processes ONS follows as a routine. However, the scale and importance of the issues is larger than usual. It would have been unwise to presume that there would be no methodological issues arising from the turbulence in the economy, following a prolonged period of relatively stable growth. Accordingly, an early internal review of the potential impact of the recession led to agreement on 13 key tasks, related to the issues shown at different stages of the SVC. Work was also initiated on financial statistics and public sector classification, covered later in this article. Progress on the tasks is set out below. Some have been completed, others will be completed later in 2010 .

\section{Task 1 - Identify issues for a} methodology research programme into producing statistics during major economic change

A scoping paper set out what research was necessary and how it might be taken forward, leading to the other work set out below.

\section{Task 2 - Identify and plan work} needed relating to large sector reclassifications of UK banks and also business failures

Work has been carried out to develop and document a consistent approach across the Office to providing and using data affected by the reclassifications. This maintained the ability to include public sector units in outputs consistently and appropriately. The work covered issues of timing, backcasting (including discontinuity measurement), disclosure, and consultation with key stakeholders. It reinforced existing procedures relating to business failures. This work is largely complete. 
Task 3 - Analyse the impact of the annual (January) update of business register for classification and other changes

Most ONS business surveys experience register changes at the January update. Our aim is to ensure early warning of potential large scale changes in the register that have the potential to introduce disturbances in survey outputs, for example if decreases in employment move current sample members to a lower sizeband.

Task 4 - Review automated imputation, editing and outlier identification parameters ONS uses imputation and editing where necessary in producing estimates from survey responses. Methodology Directorate identified the need to review imputation and editing methodology in the context of change in direction of period on period movements, and possible reduction in response rates. The methods continue to perform satisfactorily, and it has not been necessary to make any methodological changes in imputation and editing.

Task 5 - Analyse assumptions underpinning standard estimation (particularly deaths and births) and potential impact on survey outputs For larger companies, changes to the business register (including deaths and births) are generally recorded quickly and so standard estimation automatically handles these appropriately. For smaller companies, in sampled strata only, register changes (including reclassifications, changes in employment and turnover, deaths and births) rely primarily on VAT and PAYE administrative sources which take some time to become available. An issue arises in estimation for smaller companies, since sample 'deaths' are immediately known but no corresponding immediate information on 'births' is available. If no adjustment is made for unknown births then a downward bias is created, although the effect is mitigated in the next period when any sample death is replaced by another sampled company. Therefore ONS has for many years routinely adjusted its estimates very slightly upwards using a standard assumption that the net change in smaller companies each period is zero. In a recession, with presumably more deaths than births, then the validity of this assumption is more questionable and could in theory lead to a slight upward bias, via the sampled strata. ONS is considering whether variation of the standard assumption would improve estimation and how to work out when the assumption should change and change back in practice.

Task 6 - Review population estimation methodology to assess the potential for changes in migration patterns, as a result of rapid economic decline, to impact on population estimation and thus household survey weights

The recession is clearly having an effect on migration and ONS needs to ensure this is taken into account in population estimates. Before the recession began, ONS was already leading a large programme of work to improve migration estimates. Elements of this programme are associated with improving methods, sources and timeliness of the statistics to ensure they are appropriate and capable of detecting and measuring changes in patterns quickly.

Task 7 - Check effect of changes to weights on index number movements Some outputs combine their components using weights which are updated annually, and which therefore do not immediately react to widespread business failures and reclassifications but may be subject to large changes at the annual update. A theoretical study concluded that any effect should be no greater than 0.1-0.2 per cent per annum, which is well within the bounds of sampling and other errors. This conclusion was confirmed by an empirical analysis of the Index of Production.

\section{Task 8 - Review seasonal adjustment} and forecasting

ONS Methodology Directorate provides support for survey output areas on validation checks to apply to seasonally adjusted series, so that irregular events are identified and dealt with appropriately. Methodology Directorate is also investigating how best to handle sharp turning points in forecasting. In advance of the completion of these investigations, rapid response methodological support is provided to business areas regarding a sensible balance of mathematical and judgemental forecasts. More detail on this topic is given below.

\section{Task 9 - Test and produce the} 'economic story'

Recent circumstances have increased the premium on ensuring that ONS economic outputs are broadly coherent and make economic sense, with additional analysis and explanation of any divergences. Accordingly, we have made increasing use of specialist economist skills, not only to interpret the statistics and tell their story, but also to stress test statistical outputs, reviewing data to be published on a hypothesis driven approach. Enhanced interpretation and analysis has been underpinned by economists' closer engagement with the production of economic statistics and with key stakeholders.

\section{Task 10 - Consult other National} Statistical Institutions (NSIs)

Martin Brand, Deputy Director of Methodology in ONS gave a presentation on the approach in this article at a European meeting on business statistics in Stockholm in September 2009. Work was also reported to an OECD working party on finance statistics in November 2009. Other countries have commented favourably on the ONS approach.

\section{Task 11 - Document methods and systems}

Internal documentation is maintained on adjustments.

\section{Task 12 - Consider effect on non- response}

Response rates are monitored continually. Initially there were concerns that the recession might increase non-response by businesses. ONS has a comprehensive response targeting process, where dedicated teams ensure key respondents are contacted regularly. Table 1 shows that response rates for all major economic surveys have continued to meet or exceed targets, ensuring quality estimates are still being produced.

\section{Task 13 - Analyse assumptions} underlying short-term GDP statistics Short-term early estimates for GDP necessarily involve a range of assumptions. For example that turnover is a good proxy for value added. The economic underpinning of such assumptions, and their implications for interpretation, are kept under review.

\section{Examples of checks on methods in recession: seasonal adjustment and nowcasting} Seasonal adjustment (using X -11-ARIMA and X-12-ARIMA software) is used widely across the ONS. Seasonal variation may change gradually over time: for example different patterns of shopping before Christmas, or price discounting practices by stores, and this is identified in regular 
Table 1

Business survey response rates 2008-2009

Per cent

\begin{tabular}{lrrrrrrrrr}
\hline & $\begin{array}{r}\text { Response rate } \\
\text { target (by no. of } \\
\text { questionnaires) }\end{array}$ & Mar & Jun & Sep & Dec & Mar & Jun & Sep & Nov \\
Survey & 75 & 73 & 76 & 75 & 77 & 75 & 77 & 78 & 79 \\
\hline MIDSS & 75 & 75 & 76 & 78 & 78 & 80 & 79 & 80 & 82 \\
MPI & 83 & 83 & 85 & 84 & 85 & 85 & 87 & 86 & 83 \\
MWSS & 82 & 82 & 84 & 85 & 85 & 85 & 85 & 85 & 88 \\
PPI (first stage) & 60 & 60 & 60 & 61 & 63 & 61 & 62 & 64 & 63 \\
RSI & 6008 & 2008 & $\mathbf{2 0 0 8}$ & $\mathbf{2 0 0 9}$ & $\mathbf{2 0 0 9}$ & $\mathbf{2 0 0 9}$ & $\mathbf{2 0 0 9}$ \\
\hline
\end{tabular}

Source: ONS Methodology Directorate

Table 2

\section{Review of nowcasts used in estimates of quarterly GDP}

\begin{tabular}{lll}
\hline Output & Extent of Nowcasting & Reviews \\
\hline GDP(0) & M1 56\% is nowcasted & The indices are nowcasted at a very low level, meaning thousands \\
M2 33\% is nowcasted & of nowcasts. Attention has been focused on the nowcasts that fail \\
v3 20\% is nowcasted & validation checks. \\
IOP & IOP do a nowcast for M1 release of GDP, & ONS use a modified Holt Winters nowcast methodology, by nowcasting \\
only 2 months of data are available so 3rd based on different lengths of historical data: testing a 10 year, 6 year, 3 \\
month is nowcasted. & year and 6 month span and then using an appropriate forecast based \\
IOP publications do not include nowcasts. & on expert knowledge of particular sectors \\
M1 61\% is nowcasted & The indices are nowcasted at a very low level, meaning thousands \\
M2 38\% is nowcasted & of nowcasts. Attention has been focused on those nowcasts that fail \\
M3 27\% is nowcasted & validation checks.
\end{tabular}

Source: ONS Methodology Directorate

Figure 1

ONS best practice for dealing with turning point issues

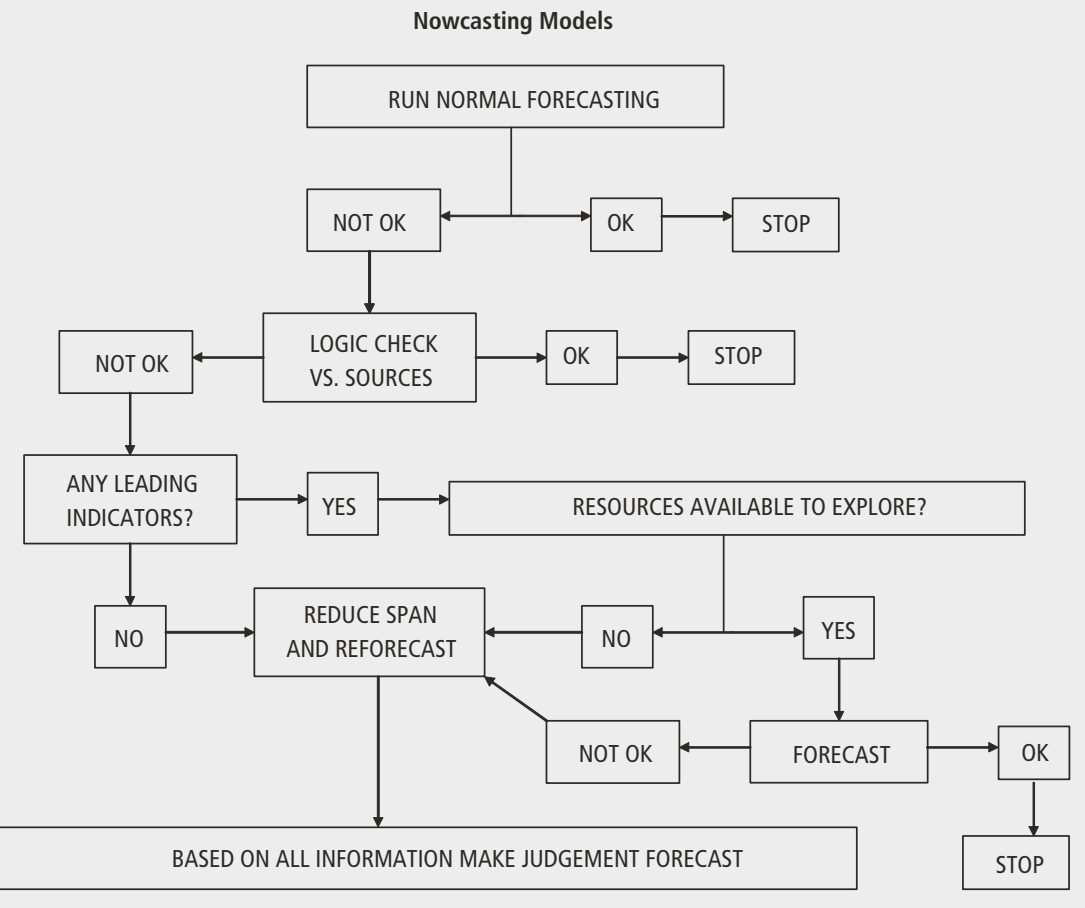

Source: ONS Methodology Directorate

reviews of seasonal adjustment parameters. Although the seasonal adjustment process can also involve the use of forecasting methods in order to produce high quality estimates at the current end of the time series, the seasonal factors based on these forecasts have remained robust during the economic downturn. the most recent period showed decline. At some date, the pattern may be expected to reverse, with the most recent period beginning to show growth but the data used in nowcasting still including a period of decline. It follows that, without statistical validity checks, nowcasts (generated by mathematical models from past data) could potentially understate the decline in economic output in the relatively early part of a recession, or potentially understate growth in the relatively early stage of recovery. A key issue affecting the speed of response of the nowcast to economic changes is the length of the period of historic data used in estimation.

Nowcasting models are mainly limited to use in the month one GDP estimate (M1), and some of the data sources that feed into the M1 estimate. M1 is affected more than month 2 or month 3 as more of M1 is nowcasted. A comprehensive framework has been used internally to quality assure estimates, based on use of the structured decision tree shown in Figure 1.

Table 2 gives more details of nowcasts used in the estimates of quarterly GDP. In practice, nowcasts involve some degree of statistical judgement. Judgements can be tested by rigorous review of revisions: an article on GDP revisions (www.statistics. gov.uk/elmr/12_09/downloads/ELMR_ Dec09_Brown.pdf) demonstrated that the revision of GDP results from first estimate to month 3 remain within historical bounds. For example, revisions triangles released with the Gross Domestic Product Preliminary estimate third quarter GDP show that revisions to early estimates are on average: 0.03 percentage points between the month 1 and month 2 estimates, 0.08 between the month 2 and month 3 estimates, and 0.21 between the month 3 estimate and the equivalent estimate 3 years later (see GDP Preliminary Estimate, 2009 Q3, available at www.statistics.gov. uk/pdfdir/gdp1009.pdf). Detailed revision analysis of all economic statistics is published regularly.

\section{Case studies: particular examples during 2009}

ONS statisticians and economists regularly review various aspects of the sources and methods of each economic output, as part of our commitment to quality (www.ons. gov.uk/about-statistics/methodology-andquality/quality/quality-strategy/index. html). In addition, each month's results are scrutinised for coherence with other statistics, and concerns may be identified - either within ONS teams, through 
dialogue with colleagues in bodies such as the Bank of England, Treasury and research bodies, or by monitoring public reaction and concerns. The aim is to quickly deploy project teams to investigate and resolve issues. This may lead to specific improvements in the method, or to a better understanding of the relevant issues. Proposals for significant changes in methods are discussed with users and will be explained in articles in ELMR or on the ONS website. Analytical articles explaining drivers of change in particular sets of economic statistics also result from these projects.

\section{Retail sales index}

One recent example is the change in the retail sales index, where McLaren (2009) explained that a new chain linked series was being introduced, with other changes in methods. This was a planned improvement (unrelated to the recession) which ensured the most up to date methodology was used to derive the Retail Sales estimates. During this period, supplementary notes published alongside the monthly releases explored topical issues such as differences between the official estimates and those published by alternative sources, and differences in trends in retail sales between smaller and larger companies. This work was summarised in Anagboso (2009). This example shows ONS's concern to explain the story of the statistics, in the current economic context, as well as improving our consistency with recognised international best practice for deriving retail sales estimates.

\section{Construction}

Another example of project work in 2009 was exploration of the figures for construction output and construction workforce. The project examined recent trends, which were more robust for workforce than the corresponding output figures, and sought explanations. This includes considering the aspects of current sources and methods which are relevant to interpreting the trends.

Measuring construction output and employment is difficult because of the complexity (size and breadth of activity) of the industry and difficulties measuring construction employment. The current methodology for measuring construction employment differs from that for other industries. Generally, Workforce Jobs are constructed as the sum of employee jobs (derived mainly from employer-based surveys) and self-employment jobs (derived from the Labour Force Survey (LFS)). In the construction industry, the LFS, which is a household survey, is used in the short term to estimate construction employee jobs, with the result then benchmarked to the Business Register \& Employment Survey (formerly ABI1). The Workforce Jobs figures give a better industrial breakdown in classification but have the disadvantage of adding employment components from different sources, which can lead to double counting or under enumeration.

There are plans to move to a new monthly survey of construction output from January 2010, with first results of the monthly survey to be published in July 2010 (www.ons.gov.uk/about/consultations/ consultation-on-construction-statistics/ index.html). Construction output is currently only measured quarterly, with GDP month 1 and 2 estimates based on an Experian forecast. From January 2010, 2 months' construction survey data in the relevant quarter will be available for use in the GDP Month 1 estimate, and all the relevant quarter's construction survey data will be available for use in the Month 2 GDP estimate. This will reduce uncertainties in the month 1 and month 2 GDP estimates. The survey will also collect employment data on a quarterly basis, which could in future be used as a measure of Workforce Jobs. Pending improvements to data sources, the output and workforce time series for construction can be used as a cross check on each other to help interpretation.

There are several factors that explain why there has not been a fall off in construction employment of the same order as for output. One possibility is greater flexibility in the construction labour market, compared with other sectors of the economy, given the extent of self employment and the possibility of becoming, or remaining, self employed rather than becoming unemployed or economically inactive. Other factors that potentially explain the divergence between construction output and employment figures include lag effects, and structural changes in the UK economy such as changes in the numbers of small construction businesses and migrant workers. These issues will be explained in detail in an ELMR article in early 2010.

\section{Household expenditure}

Another current project is exploring the differences in recent trends between figures for household expenditure, in the sector accounts, and the retail sales index. There are well documented reasons why these series will be different, including the conceptual basis of what is being measured. For example, retail sales figures include purchases made by visitors to the UK, while household expenditure estimates include only those goods purchased for consumption in the UK. Goods purchased by businesses from retail stores are included in retail sales, but not in household expenditure. However, it is important to be able to demonstrate the extent to which these and other differences affect the published estimates, in current economic circumstances. The current project is exploring the specific reasons for recent divergence between the series. Results will be reported in ELMR.

\section{Labour market analysis}

Since the onset of the recession, ONS has undertaken a range of analytical work to assess the impact on the UK labour market. In May 2009, ONS published an analytical report that examined the state of the labour market up to Q1 2009 (see Barham et al 2009). This showed how the main labour market indicators had changed direction after the sustained period of economic growth. It compared the recent changes with the two previous recessions and also looked at the differences by region, sex, age group and the impact on households. The report was presented at a seminar in London on 14 May 2009, to analysts from across central government. Professor Alan Manning, London School of Economics and Nigel Meager, Director of the Institute of Employment Studies gave commentary. Other analysis has looked at how the recession has affected workless household rates (see ONS 2009) and also the factors that affect durations of unemployment (see Long 2009).

In November 2009, ONS produced another major report on the labour market in recession, updating the previous analysis to Q3 2009. It gave more information about the sub-national picture, to show how the labour market has been affected in different parts of the UK. This report also looked at the differences in urban and rural areas and by deprivation level (see Jenkins and Leaker 2009). This report was also presented at a seminar in London to central and local government analysts; Professor Paul Gregg, University of Bristol also presented.

Working with DWP, ONS contributed to a review of the differences in trend between unemployment figures and the claimant count. This work was undertaken to look at reasons for the apparent divergence between the changes in these measures. There are 
a number of reasons for the differences between these estimates but in essence it is because they measure different things; the claimant count the number of people claiming unemployment related benefit and unemployment the number of people actively seeking work and available to start work. Once put onto a more comparable basis, the changes in the two measures have been similar over the recession, although at times the two measures have diverged slightly, for example between October 2008 and March 2009 the claimant count rose faster than unemployment. Overall, these small differences in the trend appear to be mainly down to methodological differences between the two sources. Further work on this topic may be published by DWP; ONS also plans to publish relevant statistical analysis.

\section{Improving financial statistics for policy}

In common with National Statistical Institutes around the world, ONS has been considering whether recent economic and financial events have revealed deficiencies in the available statistics, or alternatively whether messages from those statistics which were available were not given enough prominence. Such discussions are taking place under the auspices of the International Monetary Fund (IMF), OECD and other international bodies, and ONS is playing a full part in them.

In this regard, ONS has several roles:

- To provide the tools to help policymakers and analysts to understand the mechanics of the credit boom, and asset and debt inflation more generally

- To keep pace with financial innovation in our measurement of gross value added by the financial sector, and in our measurement of sectoral balance sheets

- To contribute to a fuller understanding of the public sector balance sheet so that all of the main actual and contingent liabilities are shown clearly and transparently.

To work towards these objectives, ONS launched a project in the autumn of 2008. A series of articles reporting progress were published in the July edition of ELMR. These set out planned actions, which are now being taken forward.

A major focus of the project is on financial balance sheets. UK macroeconomic policy in recent years, with its emphasis on promoting growth within a stable macroeconomic environment, has been supported by measures of output (GDP) and productivity. There has been less policy focus on sectoral balance sheets (financial and non-financial). This project points to ways in which balance sheets, using the best available data and analysis, could be helpful in analysing current economic conditions and in anticipating future pressures.

A seminar was held with key stakeholders (HM Treasury, Bank of England, Financial Services Authority (FSA), members of the Financial and Economic Statistics User Group) to present the issues raised in the papers in the July ELMR and to discuss ways forward. The session was well attended and the papers well received. Collaboration with many of these stakeholders will be an essential ingredient of good progress, both in terms of accessing additional data sources and the availability of specialist expertise. We are now building these partnerships.

Since the seminar, ONS has been addressing each of the 14 recommendations and the ELMR article. A more detailed progress report will be published in ELMR in the spring. The work was also recently presented to a meeting of the OECD Working Party on Financial Statistics; feedback was generally positive, with the issues being similar across member countries.

\section{Public finance and public service efficiency}

The path of the financial crisis has led to new financial interventions which have caused a major increase in public sector net debt while at the same time the recession has led to increased public sector borrowing. This requires ONS to determine whether particular bodies (for example Lloyds and Royal Bank of Scotland) have moved into the public sector and to classify the schemes and the transactions involved in them. ONS makes decisions based on international guidance, careful use of precedents and detailed study of legal documents for particular government interventions. The process has to be well documented and transparent. An outline of key issues on classification was included as part of the ELMR special edition on 'Developing financial statistics for policy' (see O’Donoghue (2009) and MaitlandSmith (2009)). A fuller article, explaining the ONS decisions on the National Accounts classification of the financial crisis interventions by public sector authorities between 2007 and August
2009, was published on the ONS website in November 2009 (see Kellaway 2009). Work continues, in particular to measure the assets and liabilities of the main new public sector bodies, as required as part of our public finance statistics. This is being taken forward jointly with the Bank of England and HM Treasury.

ONS public finance statistics show an increase in public borrowing and debt, issues of importance for future policy. ONS has implemented new measures of Public Sector Net Debt and Public Sector Net Borrowing into Public Sector Finance statistics, with definitions which exclude the temporary effects of the financial interventions. The PSNB ex measure will allow progress to be assessed against the Financial Consolidation Plan announced in the Pre-Budget Report.

Public spending is also a component of ONS work on measurement of public service productivity. The latest estimates for public service productivity change, between 1998 and 2007, can be found in Munro and Phelps (2009); Patterson (2009) provides an update on progress in implementing the recommendations made by the Atkinson Review (2005) on measurement of public service costs, output and productivity. An international conference, hosted by ONS and the National Institute of Economic and Social Research (NIESR) in Cardiff in November 2009, discussed measurement of public service output in the national accounts, including theoretic and practical approaches to measuring the quality of public services as part of the quantitative measures of public service output.

\section{Conclusion}

ONS statistics are produced in ways which ensure risks to statistical quality are identified and addressed systematically. Particular issues are identified and explored in project work, aiming for transparent communications about method changes or developments. Extra steps have been taken to promote economic statistics and analysis effectively to different audiences.

\section{CONTACT}

四elmr@ons.gov.uk

\section{REFERENCES}

Anagboso M (2009) 'The impact of the recession on retail sales volumes', Economic and Labour Market Review, (August 2009), vol 3, no 8, pp 22-28, available at www.statistics.gov.uk/cci/article. asp? $\mathrm{id}=2259$ 
Barham C, Hicks S and Jenkins J (2009)

'The impact of the recession on the labour market', available at

www.statistics.gov.uk/cci/article.

asp? ID $=2187$

Jenkins J and Leaker D (2009) 'The labour market across the UK in the current

recession', available at

www.statistics.gov.uk/cci/article.

asp? ID $=2310$

Kellaway M (2009) 'Public sector

interventions in the financial crisis', available at

www.statistics.gov.uk/cci/article.

asp? ID $=2301$

Long K (2009) 'Unemployment durations: evidence from the British Household Panel Survey, Economic and Labour Market Review,
(August 2009), vol 3, no 10, pp 48-54, available at

www.statistics.gov.uk/cci/article.asp? $\mathrm{id}=2295$

Maitland-Smith F (2009) 'Government

financial liabilities beyond public sector net debt', Economic and Labour Market Review, (July 2009), vol 3, no 7, pp 43-50, available at www.statistics. gov.uk/cci/article. asp? $i d=2251$

McLaren C H (2009) 'Changes to the retail sales methodology', Economic and Labour Market Review, (June 2009), vol 3, no 6, pp 66-70, available at

www.statistics.gov.uk/cci/article. $a s p ? i d=2220$

Munro F and Phelps M G (2009) 'Total public sector output and productivity', Economic and Labour Market Review, (August 2009), vol 3, no 8, pp 45-55, available at www.statistics. gov.uk/cci/article. asp? $i d=2261$
O'Donaghue J (2009) 'The public sector balance sheet', Economic and Labour Market Review, (July 2009), vol 3, no 7, pp 37-42, available at

www.statistics.gov.uk/cci/article. asp? $i d=2250$

ONS (2009) 'Work and worklessness among households', available at www.statistics.gov.uk/statbase/product. asp?vlnk $=8552$

Patterson H (2009) 'Progress in implementing the Atkinson Review recommendations', Economic and Labour Market Review, (August 2009), vol 3, no 8, pp 39-44, available at

www.statistics.gov.uk/cci/article.

asp? $\mathrm{id}=2264$

\section{ANNEX}

Table A1

Potential impact of recession on statistical quality at different parts of the statistical value chain

\begin{tabular}{|c|c|c|}
\hline SVC Step & $\begin{array}{l}\text { Potential Effect of Recession } \\
\text { and Financial Crisis }\end{array}$ & Impact on Statistical Data Quality \\
\hline $\begin{array}{l}\text { 1. Decision to undertake a } \\
\text { collection or analysis }\end{array}$ & $\begin{array}{l}\text { a. Data availability weak in areas } \\
\text { of current economic importance } \\
\text { b. Changes in boundary of public } \\
\text { sector may require additional data } \\
\text { provision, to meet requirements } \\
\text { on public finance }\end{array}$ & $\begin{array}{l}\text { Finance sector not covered adequately by } \\
\text { surveys, particularly affecting balance sheets } \\
\text { Public sector borrowing and deficit not fully } \\
\text { estimated until data available from all bodies } \\
\text { with relevant classification }\end{array}$ \\
\hline
\end{tabular}

2. Collection design

3. Accessing administrative data

5. Implementing design

6. Implementing collection

7. Editing and validation, derivation and coding

8. Weighting and estimation
No impacts identified

c. Lags in administrative data may Bias where administrative data used directly mean that differences between them and the current reality are larger than under normal conditions

d. Various industries affected differently by recession

Additional administrative data may be needed to meet gaps, for example on financial sector

Sample designs less optimal (increased sampling variance)

e. More deaths and fewer births
f. Large companies more likely to
be in administration

Smaller responding sample sizes

Harder to collect information, need coherent approach across surveys

g. Changes in industry Increased variance; more changes of stratum classification or size-band more when register "frozen" fields are updated in likely [as businesses adjust to January changing conditions?].

h. Higher rates of non-response

More follow-up (costs)

Increased sample to maintain responding

sample sizes (costs)

Increased sample and increased deaths implies more churn and therefore increased variance of changes

i. Poorer quality of responses Increased validation failures, therefore increased Medium - Task 4 follow-up costs

h. Higher rates of non-response Fewer units in imputation classes leads to increased variance

i. Poorer quality of responses Bias in estimates

j. Assumptions behind imputation Bias in imputation/ construction and construction methods violated

e. More deaths and fewer births data
Likelihood of significant

effect Existing robustness

High - Project on improving Known gaps were seen to have greater financial statistics for policy relevance in current conditions

High - work with Bank of

England to access relevant

data for public sector banks

Low - few economic outputs Most administrative data is used in use unadjusted administrative conjunction with up-to-date survey information
Low

High - Task 5

High - Task 2

High - Task 3

Medium - Task 12

Monitor response rates

sample design optima are robust to changes; sample designs are reviewed regularly 
Table A1 - continued

\begin{tabular}{|c|c|c|c|c|}
\hline SVC Step & $\begin{array}{l}\text { Potential Effect of Recession } \\
\text { and Financial Crisis }\end{array}$ & Impact on Statistical Data Quality & $\begin{array}{l}\text { Likelihood of significant } \\
\text { effect }\end{array}$ & Existing robustness \\
\hline & $\begin{array}{l}\text { c. Lags in administrative data may } \\
\text { mean that differences between } \\
\text { them and the current reality } \\
\text { are larger than under normal } \\
\text { conditions }\end{array}$ & $\begin{array}{l}\text { Poor relationship between response variables } \\
\text { and auxiliary variables leading to increased } \\
\text { variance }\end{array}$ & Low & $\begin{array}{l}\text { Estimation method already compensates } \\
\text { for changes in relationship between } \\
\text { response and auxiliary variables }\end{array}$ \\
\hline & k. More or more extreme outliers & Increased variance & Low - Task 4 & $\begin{array}{l}\text { Outlier detection and adjustment } \\
\text { procedures already in place }\end{array}$ \\
\hline & e. More deaths and fewer births & $\begin{array}{l}\text { Smaller responding sample sizes leading to } \\
\text { increased variance }\end{array}$ & Medium & \\
\hline & $\begin{array}{l}\text { I. Changed migration patterns } \\
\text { mean population estimates don't } \\
\text { reflect actual composition }\end{array}$ & $\begin{array}{l}\text { Weighting totals for social surveys don't reflect } \\
\text { actual population }\end{array}$ & Low on national estimates & $\begin{array}{l}\text { Annual updating using migration } \\
\text { patterns measured by International } \\
\text { Passenger Survey (IPS) }\end{array}$ \\
\hline \multirow[t]{2}{*}{ 9. Analysis of primary outputs } & m. More unusual movements & $\begin{array}{l}\text { Explanations for movements in series based } \\
\text { on fewer historically similar periods, therefore } \\
\text { less reliable }\end{array}$ & $\begin{array}{l}\text { Certain - a recession is an } \\
\text { unusual movement }\end{array}$ & \\
\hline & $\begin{array}{l}\text { c. Lags in administrative data may } \\
\text { mean that differences between } \\
\text { them and the current reality } \\
\text { are larger than under normal } \\
\text { conditions }\end{array}$ & $\begin{array}{l}\text { Bigger differences between administrative } \\
\text { sources and survey estimates than under normal } \\
\text { conditions }\end{array}$ & Medium - Task 9 & $\begin{array}{l}\text { Commentary and briefing already } \\
\text { provided }\end{array}$ \\
\hline \multirow[t]{3}{*}{$\begin{array}{l}\text { 10. Index number } \\
\text { construction }\end{array}$} & $\begin{array}{l}\text { n. Major revisions to index when } \\
\text { rebasing to or from a recession } \\
\text { year }\end{array}$ & & $\begin{array}{l}\text { Low - recession does not fall } \\
\text { in rebasing year }\end{array}$ & $\begin{array}{l}\text { Chainlinking protects against revisions } \\
\text { from rebasing }\end{array}$ \\
\hline & $\begin{array}{l}\text { f. Large companies more likely to } \\
\text { be in administration } \\
\text { r. PRODCOM product breakdowns }\end{array}$ & $\begin{array}{l}\text { Large business failures mean index weights are } \\
\text { out of date }\end{array}$ & Medium - Task 7 & \\
\hline & change quickly & $\begin{array}{l}\text { Weights for PPIs, based on previous year's } \\
\text { PRODCOM, are out of date }\end{array}$ & Medium & \\
\hline \multirow[t]{3}{*}{ 11. Time series analysis } & $\begin{array}{l}\text { o. Change in seasonal pattern } \\
\text { (particularly moving seasonality, } \\
\text { level shifts) }\end{array}$ & $\begin{array}{l}\text { Increased uncertainty about seasonal } \\
\text { adjustment until enough data points for new } \\
\text { pattern to become established; more revisions }\end{array}$ & High - Task 8 & $\begin{array}{l}\text { Regular seasonal adjustment reviews } \\
\text { keep models up to date }\end{array}$ \\
\hline & $\begin{array}{l}\text { p. Forecasts continue to increases } \\
\text { after series turn down }\end{array}$ & Forecasts not credible & $\begin{array}{l}\text { High - Task } 8 \text { This is a natural } \\
\text { consequence of using long } \\
\text { filters to remove noise }\end{array}$ & $\begin{array}{l}\text { Forecasts are reviewed for credibility } \\
\text { before use }\end{array}$ \\
\hline & k. More or more extreme outliers & $\begin{array}{l}\text { Increased uncertainty about seasonal } \\
\text { adjustment; more revisions }\end{array}$ & Low & $\begin{array}{l}\text { Outlier detection and adjustment } \\
\text { procedures already in place; regular } \\
\text { seasonal adjustment reviews keep outlier } \\
\text { assessments up to date }\end{array}$ \\
\hline \multirow[t]{3}{*}{$\begin{array}{l}\text { 12. Further analysis (across } \\
\text { datasets) }\end{array}$} & $\begin{array}{l}\text { q. Reduced accuracy of } \\
\text { short-term output indicators as } \\
\text { measures of GVA }\end{array}$ & Increased bias in estimation of GVA & Medium - Task 13 & \\
\hline & $\begin{array}{l}\text { s. Major revisions to GDP when } \\
\text { supply-use balancing applied for } \\
\text { a recession year (bias) }\end{array}$ & $\begin{array}{l}\text { When input-output tables available for weights } \\
\text { for recession year, balance of activity between } \\
\text { industries shifts and causes revisions to GDP }\end{array}$ & $\begin{array}{l}\text { High, but impact only } \\
\text { quantifiable when input- } \\
\text { output tables available } \\
\text { (currently several years after } \\
\text { the event) }\end{array}$ & \\
\hline & $\begin{array}{l}\text { I. Major changes in inputs } \\
\text { (specifically migration) may } \\
\text { impact on accuracy of analytical } \\
\text { outputs (population estimates) }\end{array}$ & & High - Task 6 & \\
\hline $\begin{array}{l}\text { 13. Confidentiality and } \\
\text { disclosure }\end{array}$ & e. More deaths and fewer births & $\begin{array}{l}\text { Smaller responding sample sizes, so more } \\
\text { outputs might be disclosive }\end{array}$ & High & $\begin{array}{l}\text { Disclosure control mechanisms already in } \\
\text { place to maintain confidentiality }\end{array}$ \\
\hline \multirow[t]{2}{*}{$\begin{array}{l}\text { 14. Dissemination of data and } \\
\text { metadata }\end{array}$} & $\begin{array}{l}\text { t. Greater uncertainty in estimates } \\
\text { near turning points (covers } \\
\text { several other factors above) }\end{array}$ & $\begin{array}{l}\text { Interpretation more difficult at just the moment } \\
\text { users want more certainty }\end{array}$ & Task 9 & $\begin{array}{l}\text { Provide commentary and briefing to } \\
\text { indicate quality and set outputs in proper } \\
\text { economic context }\end{array}$ \\
\hline & $\begin{array}{l}\text { t. Greater uncertainty in estimates } \\
\text { near turning points (covers } \\
\text { several other factors above) }\end{array}$ & $\begin{array}{l}\text { Need to justify and document procedure } \\
\text { changes and use of judgement }\end{array}$ & Task 11 & \\
\hline $\begin{array}{l}\text { 15. Data archiving and ongoing } \\
\text { management }\end{array}$ & & No impacts identified & & \\
\hline
\end{tabular}

